\title{
Therapeutic and immunological interventions in primary biliary cholangitis: from mouse models to humans
}

\author{
Atsushi Tanaka ${ }^{1}$, Patrick S.C. Leung ${ }^{2}$, Howard A. Young ${ }^{3}$, M. Eric Gershwin ${ }^{2}$
}

\begin{abstract}
${ }^{1}$ Department of Medicine, Teikyo University School of Medicine, Tokyo, Japan 2Division of Rheumatology Allergy and Clinical Immunology, School of Medicine, University of California, Davis, CA, USA

${ }^{3}$ Cancer and Inflammation Program, Center for Cancer Research, National Cancer Institute-Frederick, Frederick, MD, USA
\end{abstract}

Submitted: 11 April 2017

Accepted: 15 April 2017

Arch Med Sci 2018; 14, 4: 930-940

DOI: https://doi.org/10.5114/aoms.2017.70995

Copyright @ 2017 Termedia \& Banach

Primary biliary cholangitis (PBC) is a chronic cholestatic liver disease that predominantly affects women in their fifth and sixth decades. The diagnostic hallmarks of PBC are detection of anti-mitochondrial antibodies (AMAs) and chronic non-suppurative destructive cholangitis (CNSDC) of small- and medium-sized intrahepatic bile ducts in liver histological examination [1, 2]. A significant amount of data suggests that immunological activity against small biliary epithelial cells (BECs), found histologically as portal inflammation, leads to clinical disease. In PBC, as with other autoimmune diseases, both genetic and environmental factors contribute to the development of pathology [3-8]. The first-line therapy of PBC is ursodeoxycholic acid (UDCA), although obeticholic acid (OCA) has been approved recently for patients with an incomplete response to UDCA [9-11]. Unfortunately, unlike other autoimmune diseases, no successful clinical trials of biologics have been conducted, and the mechanisms of action of UDCA and OCA are not fully understood [12-16].

The clinical phenotype and the natural history of PBC vary between patients and can have other overlapping autoimmune diseases [12, 17-19]. For example, some patients may have mild elevation of liver enzyme levels and remain asymptomatic for life. By contrast, other patients can develop signs of liver failure and rapidly decompensate despite therapy, requiring liver transplantation. A presumption is that these differences are due to genetic and environmental factors, both contributing to the development of PBC to various degrees in each patient $[4,7,20]$. Although multiple genome-wide association studies (GWASs) have been reported differences in several genes [21-24], their clinical implications and relevance remain elusive [25]. In fact, in PBC, in autoimmune diseases, including PBC, the results of GWASs have been disappointing, and efforts have been made recently for both deep sequencing and study of epigenetic events [26-30]. To understand the importance of developing a useful mouse model, other aspects of PBC such as spectra of disease and gender dominance should be considered [18, 31].

\section{Toward solving the etiological mystery}

Most autoimmune diseases, including PBC, have a strong sex bias towards women [32, 33]. Male and female immune responses differ and

\author{
Corresponding author: \\ M. Eric Gershwin MD \\ Division of Rheumatology, \\ Allergy and \\ Clinical Immunology \\ University of California \\ Davis School of Medicine \\ 451 Health Sciences Drive \\ Suite 6510, Davis, CA 95616 \\ Phone: +1 5307522884 \\ Fax: +1 5307524669 \\ E-mail: megershwin@ucdavis. \\ edu
}


are affected by sex hormones, $\mathrm{X}$-linked genes, and sex-specific microbiota [34-38]. Despite extensive studies with clinical samples and animal models of PBC, no demonstrated physiological mechanisms account for the strong female predominance in PBC [32, 39-48]. Epidemiological studies on $\mathrm{PBC}$ show that frequent exposure to environmental chemicals such as nail polish, chemicals in tobacco smoke, and hormone replacement therapies are significantly associated with an increased risk of PBC [7]. Other PBC risk factors include recurrent urinary tract infections and increased prevalence of reproductive complications $[49,50]$. These risk factors may work synergistically in accelerating loss of tolerance. One theory proposes that haploinsufficiency for specific $X$-linked genes leads to female susceptibility to PBC and suggests that enhanced monosomy $X$ in the peripheral lymphocytes of affected women plays a role in the induction of PBC $[51,52]$. However, how these genetic and environmental factors interact with the immune system to elicit autoimmunity in PBC remains unclear [53].

Newly diagnosed PBC patients are often past their initial stages and present with elevated cholestatic enzymes, AMA positivity, and dense aggregation of lymphocytes in the liver. Investigation of these patients for very early events of PBC is therefore inappropriate, and animal models that reflect many of the important aspects of the disease are much needed. The animal model should have the same physiological mechanisms that are observed in human PBC, such as female predominance; chronic cholestasis; AMA production; histological features, including lymphocyte infiltration into the liver; and bile duct immune involvement.

\section{Efforts to establish mouse models of PBC}

Several groups including, our own, have established mouse models of PBC in a spontaneous or induced manner (Table I). These mice share some of the important clinical phenotypes of PBC, including portal lymphocytic infiltration, presence of AMA against mitochondrial antigens, and chronic cholestasis.

\section{Spontaneous murine models}

The NOD.c3c4 mice, which have multiple B6and B10-derived insulin-dependent diabetes (Idd)resistant alleles on chromosomes 3 and 4, respectively, of the non-obese diabetic (NOD) mice. NOD. C3c4 mice were demonstrated to be protected from autoimmune diabetes and spontaneously develop lymphocytic peribiliary infiltrates and AMA positivity $[54,55]$. AMAs were detectable in $60 \%$ $(3 / 5)$ and $57 \%(4 / 7)$ of mice at 9-10 weeks and 14-20 weeks of age, respectively, and were directed against the inner lipoyl domain of PDC-E2, the same mitochondrial autoantigens as recognized in human PBC [54]. Moreover, it is noteworthy that AMA detection was observed in female mice, indicating female predominance like in human PBC. However, pathological examination of the liver revealed biliary polycystic diseases in both intrabiliary and extrabiliary ducts, and little evidence of CNSDC. The expression levels of anti-PDC-E2 antibodies declined as the mice got older. Chronic biochemical cholestasis was not observed. Nevertheless, NOD.c3c4 mice clearly indicated that genetic manipulation in a susceptible strain could produce AMA with identical antigenicity as human PBC for the first time, supporting the importance of genetic contribution to PBC.

Table I. Characteristics of some PBC mouse models

\begin{tabular}{|c|c|c|c|c|c|c|}
\hline \multirow{2}{*}{$\begin{array}{l}\text { Clinical and } \\
\text { immunological } \\
\text { features }\end{array}$} & \multicolumn{5}{|c|}{ Spontaneous model } & \multirow{2}{*}{$\begin{array}{c}\text { Induced } \\
\text { model } \\
\text { 2-OA-BSA } \\
\text { immunized }\end{array}$} \\
\hline & NOD.c3c4 & dnTGFbRII & IL-2R $\alpha^{-/-}$ & Ae $2_{a, b}{ }^{-/-}$mice & ARE Del ${ }^{-/-}$ & \\
\hline $\begin{array}{l}\text { Female } \\
\text { dominance }\end{array}$ & Yes & No & No & No & Yes & No \\
\hline Cholestasis & - & + & - & Yes & + & + \\
\hline $\begin{array}{l}\text { AMA } \\
\text { seropositivity }\end{array}$ & $50-60 \%$ & $100 \%$ & $100 \%$ & $30 \%$ & $100 \%$ & $100 \%$ \\
\hline $\begin{array}{l}\text { Portal } \\
\text { inflammation }\end{array}$ & +++ & +++ & +++ & ++ & ++ & + \\
\hline Granulomas & + & - & - & - & + & + \\
\hline Other features & $\begin{array}{c}\text { Biliary } \\
\text { polycystic } \\
\text { lesions }\end{array}$ & $\begin{array}{l}\text { Moderate } \\
\text { colitis }\end{array}$ & $\begin{array}{c}\text { Severe } \\
\text { anemia, } \\
\text { inflammatory } \\
\text { bowel } \\
\text { diseases, and } \\
\text { short life span }\end{array}$ & $\begin{array}{l}\text { Osteopetrosis } \\
\text { in long bones }\end{array}$ & $\begin{array}{l}\text { Mild lupus- } \\
\text { like disease }\end{array}$ & Peritonitis \\
\hline
\end{tabular}


The dominant-negative TGF- $\beta$ receptor II (dnTGFßRII) mice, studied intensively by our group, also mimicks phenotypes of human PBC [56]. These mice are transgenic for the directed expression of a dominantly negative form of TGF- $\beta$ receptor type II, under the direction of the CD4 promoter. Thus, TGF- $\beta$ signaling is not completely abolished and dnTGF $\beta$ RII mice can survive as do non-transgenic mice. DnTGF $\beta$ RII mice spontaneously produce AMAs directed to the same mitochondrial autoantigens as in human PBC, namely PDC-E2, BCOADC-E2, and OGDC-E2. By weeks $22-24,100 \%, 95 \%$, and $68 \%$ of the mice sera reacted with PDC-E2, OGDC, and $B C O A D C$, respectively. Lymphocytic liver infiltration with periportal inflammation is analogous to the histological profile of human PBC (Figure 1). In addition, the serum cytokine profile of affected mice mimics data in human PBC. DnTGFßRII mice, although lacking female predominance, demonstrate the role of TGF- $\beta$ pathways in the immunopathogenesis of PBC and served as a model for investigating the efficacy of B-cell depletion therapy for PBC [57].

The third spontaneous mouse model is IL-2R $\alpha^{-/-}$ mice, lacking IL-2R that is crucial for differentiation of regulatory $T$ cells (Tregs) and eventually reduction in Tregs [58]. We reported the case of a 5-yearold boy with IL-2 $\alpha$ deficiency who developed liver dysfunction with serological expression of PBC, and documented paucity in the frequency and absolute numbers of circulating $C D 4{ }^{+} \mathrm{CD} 25^{\text {high }}$ natural Tregs in patients with PBC and their first-degree relatives [59]. These observations prompted us to examine whether IL-2R $\alpha^{-/-}$mice would serve as PBC model mice. The results were striking because the mice developed portal inflammation, biliary ductular damage, and a Th1 cytokine bias in sera, resembling human PBC. In addition, AMAs were detectable in all IL-2R $\alpha^{-/-}$mice and targeted to the inner lipoyl domain of PDC-E2. However, female predominance was not observed in the $\mathrm{IL}-2 \mathrm{R}^{-/-}$mice. Furthermore, absence of granulomas, short life span, and presence of clinical manifestations such as anemia and inflammatory bow- el diseases made the IL-2R $\alpha^{-/-}$mice less attractive as a PBC model mice.

The fourth spontaneous model is the Ae2a, $b^{-/-}$ mice. $\mathrm{AE} 2$ is an $\mathrm{Cl}^{-} / \mathrm{HCO}_{3}{ }^{-}$anion exchanger 2 which is involved in intracellular $\mathrm{pH}$ regulation and trans-epithelial acid-base transport. In 2008, Salas et al. reported that $\mathrm{Ae} 2 \mathrm{a}, \mathrm{b}^{-/-}$mice develop elevated levels of IL-12p70 and IFN- $\gamma$ and increased numbers of CD8+ T cells. Interestingly, AMA and increased levels of IgM, IgG and alkaline phosphatase were also observed in Ae2a, $\mathrm{b}^{-/-}$mice. Histologically, $30 \%$ of Ae $2 a, b^{-/}$mice showed infiltration of $\mathrm{CD}^{+}$and $\mathrm{CD}^{+}{ }^{+} \mathrm{T}$ cells in the portal areas and around the damaged bile duct with slight fibrosis around areas of bile duct obstruction [60].

The mechanism of this model has been explained by a change in biliary epithelial cell homeostasis due to AE2 deficiency, which increases intracellular $\mathrm{pH}$ and promotes the proliferation, differentiation and activity of lymphocytes, leading to an increase in the targeting sensitivity of $\mathrm{CD}^{+} \mathrm{T}$ cells, leading to biliary pathology. Although Ae2a, $\mathrm{b}^{-/-}$mice develop hepatobiliary and immunological features resembling human PBC, the large variations in liver pathology, lack of female predominance and difficulties in breeding made Ae2a, $b^{-/-}$mice limit its applications for preclinical studies.

\section{Induced murine models}

The three above-mentioned mice spontaneously developed serological and immunopathological features that mimic human PBC after genetic manipulation (Table I), clearly indicating the importance of genetics in the development of the disease. Meanwhile, robust evidence supports the crucial contribution of environmental factors; in this regard, stimulation of genetically susceptible mice with environmental factors would be another attractive approach for breaking immunological tolerance against PDC-E2. To establish these "induced" mice model, we have studied chemical xenobiotics as potential environmental factors, particularly and hypothesized that xenobiotic modification of native PDC-E2
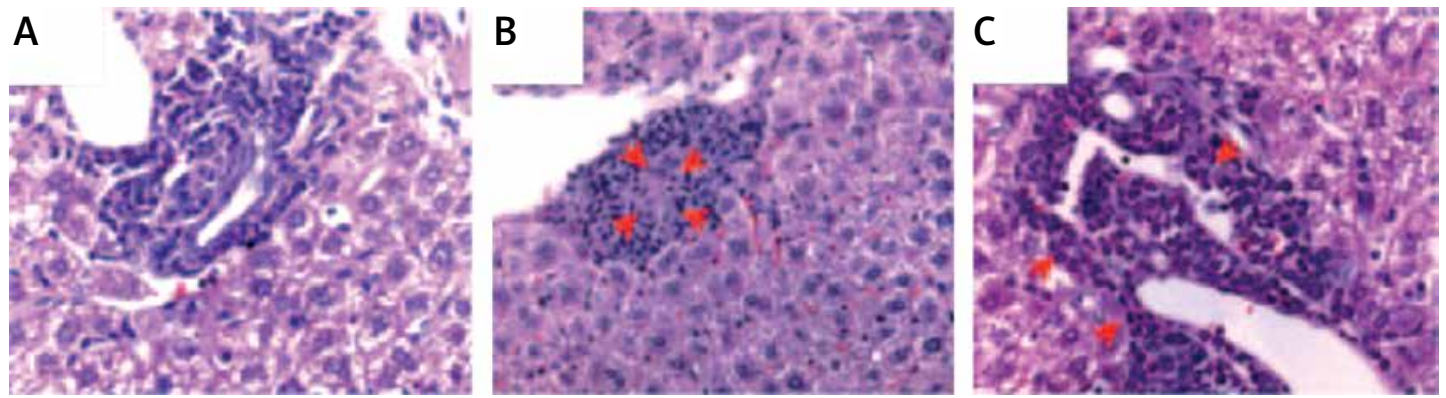

Figure 1. Histological features of the liver in dnTGF $\beta$ RII mice at 24-28 weeks. Different degrees of lymphocytic infiltrations (red arrows) surrounding the small bile ducts, within the portal tracts (hematoxylin-eosin staining) [56] 
could elicit autoimmune response to PDC-E2 and break tolerance.

Based on a detailed, quantitative structure-activity relationship analysis with 107 potential xenobiotic mimics coupled to the lysine residue of the immunodominant 15 -amino acid peptide of the PDC-E2 inner lipoyl domain, we found that PBC sera were more reactive to a number of xenobiotics modified PDC-E2 peptide than to the native lipoylated peptide. Among them, 2-Octynoic acid (2-OA) was unique in both its quantitative structure-activity relationship analysis and reactivity [20]. 2-OA is a xenobiotic chemical that is widely used as a cosmetic ingredient and for seasoning foods. Thus, we immunized C57BL/6 mice with 2-OA coupled to bovine serum albumin (BSA; Figure 2) and demonstrated that anti-PDC-E2 antibodies were seropositive as early as 4 weeks after immunization (Figure 3), indicating tolerance breakdown against PDC-E2 with xenobiotic immunization. In addition, these mice have shown portal infiltration of CD4+ and CD8+ T cells and granulomas, and elevation of TNF- $\alpha$ and IFN- $\gamma$ expression levels [61]. Therefore, 2-OA-BSA-immunized mice provides a suitable model for investigating immunopathogenesis in the early stage of PBC and for testing the therapeutic efficacy of new compounds.

To further investigate potential roles of cytokine pathways, we systemically constructed several unique gene-deleted mice, including mice with IL-12p40, IL-12p35, IFN- $\gamma$, IL-23p19, IL-17A, IL-17F, and IL-22 deletions. Then, we immunized these mice with 2-OA-BSA and followed their natural history [62]. The results are summarized as follows: (1) both IL-12/T helper type 1 (Th1) and IL-23/Th17 were involved in autoimmune cholangitis, (2) the IL-12/Th1 signaling pathway elicited pathology, and (3) IFN- $\gamma$ deletion prevented autoimmune cholangitis (Figure 4). Furthermore, 2-OA-BSA mice were also studied for the potential efficacy of CTLA-4-based therapy on cholangitis by using CTLA4-Ig [63].

In summary, these model mice develop clinical and immunological characteristics as human PBC, including cholestasis, AMA positivity, and portal inflammation. However, female predominance, an important feature of PBC and other autoimmune diseases, was not manifested in most of the mice except for NOD.c3c4 mice. A mouse model with immunological characteristics of PBC and female predominance will more closely reflect the human disease. Therefore, we focused on IFN- $\gamma$ based on extensive efforts of Dr. Howard Young et al. on a interesting IFN- $\gamma$ designer mouse, described below, and also in part on numerous studies that reported that IFN- $\gamma$ plays an essential role in the development and severity of female-dominant autoimmune diseases [34].

\section{IFN- $\gamma$ as a key molecule of PBC}

There are several lines of evidence that IFN- $\gamma$ is involved in the pathogenesis of autoimmune cholangitis: (i) Immunohistochemistry staining in PBC livers demonstrates that, IL-12/Th1 cytokines are dominant in the inflamed portal area with IFN- $\gamma$-positive monocular cells surrounding degenerated cholangiocytes in the early stage of disease, whereas the Th1/Th17 balance is skewed toward IL-23/Th17 in advanced stages of PBC [64]. (ii) As described previously, liver histology in a xenobiotic induced model demonstrated that both IL-12/Th1 and IL-23/Th17 are involved in cholangitis but indicated that the IL-12/Th1 signaling pathway elicits pathology. The disease was prevented by IFN- $\gamma$ deletion (Figure 4) $[62,65]$. (iii) Th17 signaling suppressed the accumulation of IFN- $\gamma$-producing cells in the liver during the early phase of cholangitis [62], supporting the hypothesis that IFN- $\gamma$ is a key factor in the induction of biliary autoimmunity. Thus, we emphasize that the pathology of PBC is mediated through IFN- $\gamma$-related pathways. For example, one may postulate that 2-octynoic acid

NHS-activated 2-octynoic acid BSA-conjugated 2-octynoic acid

Lipoic acid
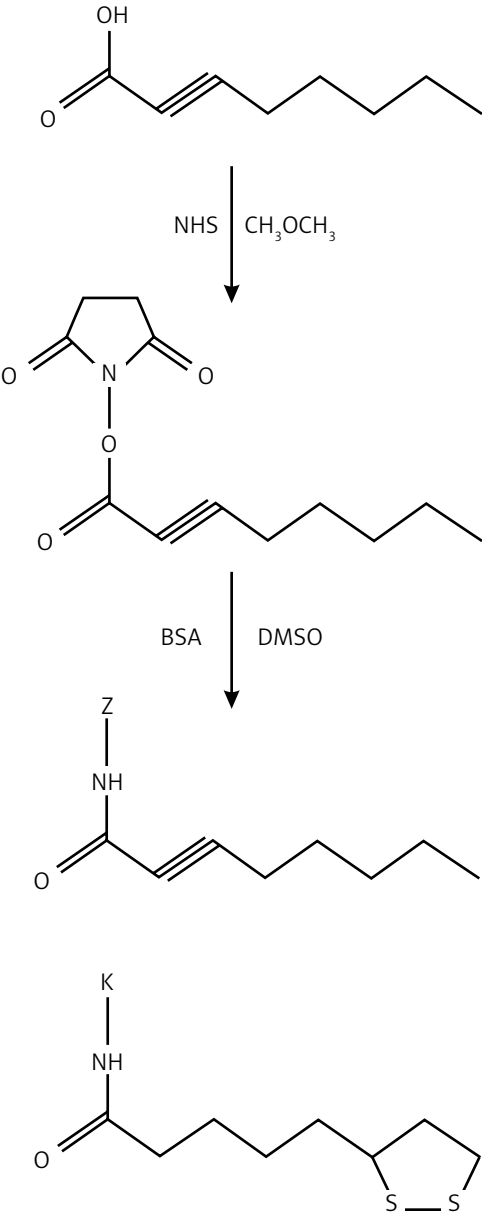

Figure 2. Structures of lipoic acid and 2OA-BSA. 2OA is conjugated with BSSA and used for immunization. "Z" represents any lysine residue of BSA. NHS, N-hydroxysuccinimide [61] 

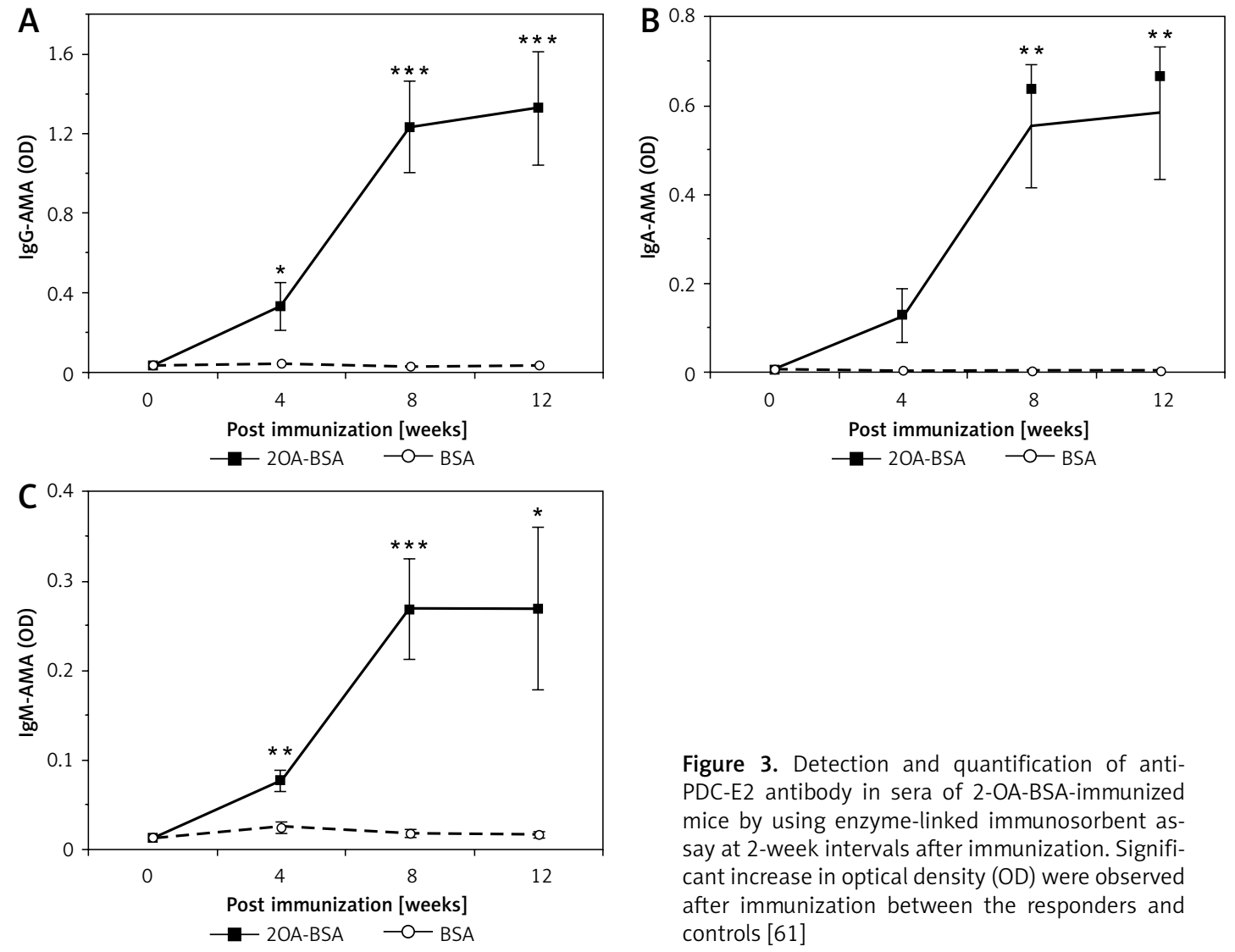

Figure 3. Detection and quantification of antiPDC-E2 antibody in sera of 2-OA-BSA-immunized mice by using enzyme-linked immunosorbent assay at 2-week intervals after immunization. Significant increase in optical density (OD) were observed after immunization between the responders and controls [61]

B6
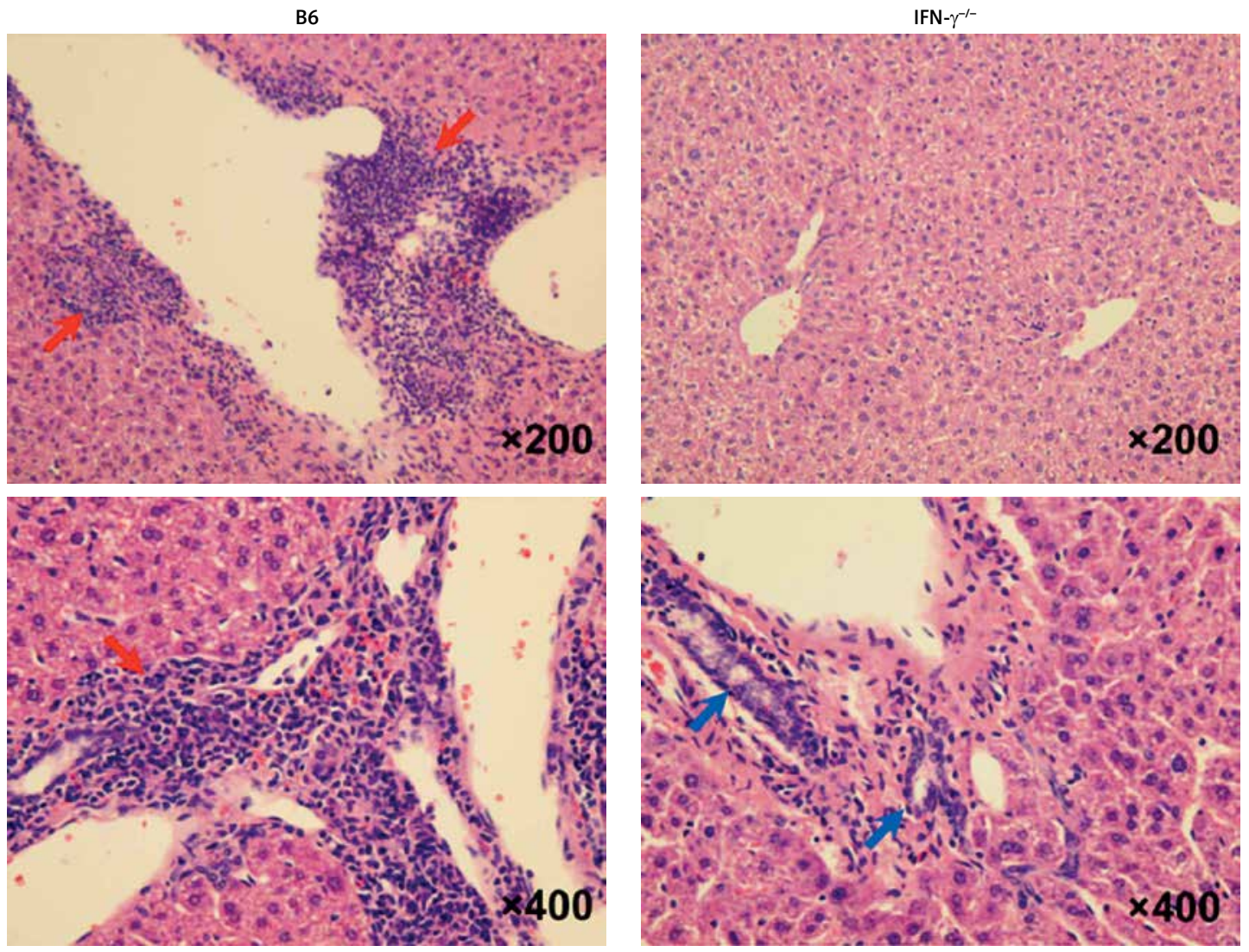

Figure 4. IFN- $\gamma$ knockout completely abolished autoimmune cholangitis. Portal inflammatory changes with interlobular bile duct damage (red arrow) were observed in wild-type mice (B6 mice) and normal bile ducts in IFN- $\gamma^{-1-}$ mice (blue arrows) [62] 
after a liver environmental insult, local up regulation of IFN- $\gamma$ in a genetically susceptible host will lead to loss of tolerance. These events may occur serially, each leading to an up regulation of $\mathrm{MHC}$ in target tissue, further contributing to an autoimmune response. We should note that activation of naive CD4 T cells from healthy women produces higher levels of IFN- $\gamma$ and lower levels of IL-17 than those from healthy men [66]. Increased IFN- $\gamma$ levels have also been demonstrated in patients with autoimmune diseases [34, 67]. However, no optimal model has been developed to determine how IFN- $\gamma$ and gender together could elicit female-biased cholangitis in patients with PBC. In particular, whether IFN- $\gamma$ is the first trigger in breaking tolerance needs to be addressed.

\section{An ARE Del ${ }^{-1-}$ mice as a novel PBC model}

To solve this problem, we took advantage of a "designer" mouse with dysregulation of IFN- $\gamma$, in which adenylate uridine-rich element (ARE) of the IFN- $\gamma$ 3'-untranslated region was deleted [68]. In these mice, regulation of IFN- $\gamma$ is disrupted and is constantly produced.

The ARE Del $^{-/}$mice have mild autoimmune manifestations similar to lupus early in life. Adult mice reflect many symptoms similar to human PBC, including liver histology, AMA production, and elevation of serum total bile acid (TBA) levels [69]. Furthermore, these features are predominantly found in female mice. In male ARE Del-1mice, portal inflammation was scarcely found, and serum titers of AMA were elevated but not significantly in comparison with those in wildtype mice (Figure 5). The TBA levels were comparable. Furthermore, gene expression analysis revealed that upregulated genes in female ARE $\mathrm{Del}^{-/-}$mice specifically overlapped with the gene expression signature of BECS in human PBC. Therefore, female ARE $\mathrm{Del}^{-/-}$mice mimic human PBC closely, making ARE Del ${ }^{-/-}$mice an ideal PBC mouse model.

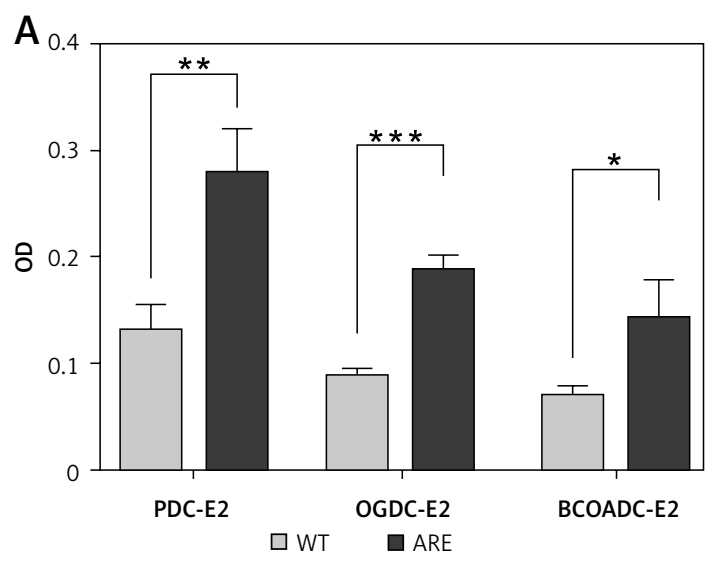

Female predominance occurs in ARE $\mathrm{Del}^{-/-}$mice probably because female hormones and genetics shape the immune system in female mice to generate more IFN- $\gamma$-producing cells. On the other hand, male mice may be protected by androgens, which favor up regulation of regulatory cells and down regulation of IFN- $\gamma$-producing cells. Female hormones activate the $\mathrm{T}$ lymphocytes to express more IFN- $\gamma$ in female mice in this mouse model. Although many spontaneous and induced murine models have been reported as PBC mouse models [65], no single model has exhibited female dominance as observed in this ARE Del ${ }^{-/-}$mice.

IFN- $\gamma$ may play a pathogenic role in BECs in the initiation stage of $\mathrm{PBC}$, and alteration of expression levels of IFN- $\gamma$ would be critical for the development of PBC in susceptible individuals. Furthermore, we demonstrated that transfer of CD4 $\mathrm{T}$ cells from ARE $\mathrm{Del}^{-/-}$mice to $\mathrm{B} 6 / \mathrm{Rag}^{-/-}$mice (an immune-deficient strain lacking mature $\mathrm{T}$ or $B$ cells) induced moderate portal and parenchymal inflammations, implying that CD4+ T cells mainly contribute to the induction of cholangitis [69].

\section{What then are the therapeutic targets in PBC?}

Although the pathogenesis of PBC is still not fully understood, progression of the disease from early to late stage is divided into 3 steps: (i) loss of tolerance against PDC-E2, which leads to inflammation and bile duct damage; (ii) insults to BECs with toxic bile acids due to chronic cholestasis; and (iii) liver fibrosis. Thus, treatment targets are mainly considered as inhibition of autoimmunity or modification of lymphocytes targeted to the liver, detoxification of harmful bile acids, and reversal of the fibrotic process [31]. As anti-fibrotic drugs are expected to be effective for all liver diseases regardless of etiologies, we will focus on the modification of autoimmunity and detoxification of harmful bile acids (Table II).

PBC is an autoimmune-mediated liver disease, and homing of autoantigen specific $T$ lymphocytes

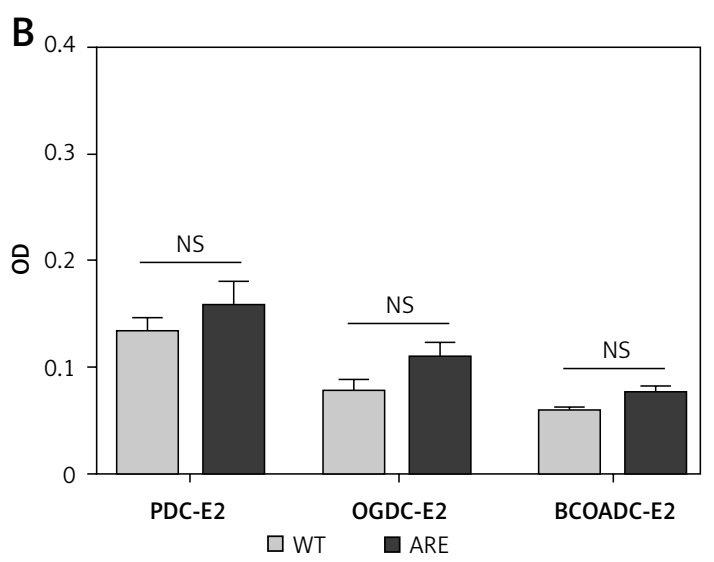

Figure 5. AMA levels in ARE-Del ${ }^{-/-}$female (A) and male (B) mice at 20 weeks [69]

$W T$ - wild type. 
to the liver plays a crucial role in its pathogenesis. However, clinical trials with immunosuppressive agents have essentially failed, including corticosteroids, methotrexate, azathioprine budenoside and select biologics. Among these trials, B-cell depletion with anti-CD20 had been expected to be effective in PBC [57]. Although non-specific inhibition of activation of T cells was thought to be a candidate for therapeutic trials, overall results from clinical trials with anti-CD40, chimeric CTLA4 (abatacept), and anti-IL12/IL23 (ustekinumab) were disappointing [70].

Biliary epithelial cells damaged by innate and/ or acquired immunity impede smooth flow of bile within the bile ducts, which leads to chronic cholestasis. In normal conditions, the "bicarbonate umbrella", a layer of secreted bicarbonate onto biliary epithelial cells, protects them from toxic bile acids. Impairment of this umbrella contributes to development of cholestasis in PBC [71]. Hydrophobic bile acids such as lithocholic acid are highly toxic to biliary epithelial cells and hepatocytes. Therefore, reducing the toxicity of hydrophobic bile acids through decreasing bile acid synthesis and stimulating choleresis would be another possible regimen in cholestatic liver diseases such as PBC [72]. So far, many compounds have been developed for detoxification of hydrophobic bile acids, and mechanisms of these drugs are largely classified into three categories: reduction of intrahepatic de novo synthesis of bile acids, choleresis through modification of hepatic bile acid transporters, and blocking bile acid transporters at the ileum for disturbing the reabsorption of bile acids [73].

\section{Modification of autoimmunity}

Rituximab that leads to B-cell depletion and ant-fractalkine antibody were expected to be effective and clinical trials are in preparation. Rituximab is anti-CD20 antibody, clinically used for several indications associated with $B$ lymphocytes such as non-Hodgkin lymphoma. B-cell depletion with anti-CD20 antibody ameliorates cholangitis in dnTGF- $\beta$ RII mice, but preliminary data in clin- ical trials suggested conflicting results [74, 75]. Recently, several novel anti-CD20 antibodies have been developed and approved for B-cell lymphoma [76] and are expected to be investigated in patients with PBC as well.

Pathogenic $T$ lymphocytes are activated and recruited into the vicinity of the bile ducts from the portal vein. During this homing process of $T$ lymphocytes, chemokines play an important role. Previous studies demonstrated that $\mathrm{CX} 3 \mathrm{CL} 1$ (a chemokine called fractalkine) production was augmented with TLR3 by biliary epithelial cells in PBC, and CX3CR1 (the receptor of fractalkine)-positive lymphocytes invade into biliary tract by engaging CX3CL1, thereby causing cholangitis [77]. Anti-fractalkine antibody (E6011), originally developed for rheumatoid arthritis [78] and Crohn's disease, is thus expected to be effective for PBC, and the phase 2 trial of E6011 for PBC with incomplete response to UDCA will be soon launched in 2017.

\section{Obeticholic acid}

Alternative treatment options for $\mathrm{PBC}$ patients refractory to UDCA have been long awaited. In 2016, the Food and Drug Administration (FDA) officially approved OCA, based on the results of the phase 3 clinical trial of OCA (POISE trial) [10]. OCA is a selective ligand of the farnesoid $X$ receptor (FXR). Bile acid toxicity against biliary epithelial cells and hepatocytes is decreased by FXR signaling through impairment of bile acid synthesis and stimulation of choleresis. The endogenous FXR ligand is chenodeoxycholic acid (CDCA), a primary bile acid. Compared with CDCA, OCA is approximately 100 times more potent than CDCA in activating FXR [79].

In the POISE trial, 217 patients with PBC who showed an inadequate response (serum alkaline phosphatase (ALP) level of $>1.67 \times$ ULN) or an abnormal total bilirubin level $(<2$ times $\times$ ULN), or intolerance to UDCA were enrolled and received 5-10 mg of OCA, $10 \mathrm{mg}$ of OCA, and placebo for 1 year. The primary end point was ALP level of $<1.67 \times$ ULN with $>15 \%$ reduction from the baseline and normal bilirubin level. Of the patients,

Table II. Pathogenic and therapeutic targets of PBC

\begin{tabular}{|lccc|}
\hline Mechanisms & Drug name & Drug class & Phase of development \\
\hline Modification of & Abatacept & Chimeric CTLA4 & Phase 4 \\
autoimmunity & Ustekinumab & Anti-IL12 Ab & Phase 2 \\
& Rituximab & Anti-CD20 Ab & Phase 2 \\
& E6011 & Anti-fractalkine Ab 2 \\
\hline $\begin{array}{l}\text { Detoxification } \\
\text { of toxic bile }\end{array}$ & Obeticholic acid & FXR agonist & Approved and phase 4 \\
acids & Fenofibrate & Fibrates & Phases 2 and 3 \\
& Bezafibrate & Fibrates & Phase 2 \\
& GSK2330672 & Inhibitors of ileal bile acid 2 & Phase 2 \\
& NGM282 & transporter & Phase 2 \\
\hline
\end{tabular}


$46-47 \%$ of patients achieved the primary end point [10]. Consequently, OCA received accelerated FDA approval on May 27, 2016.

While OCA has become the second-line drug officially approved for PBC and is well accepted, it remains suboptimal for several reasons: First, the response rate was at most $50 \%$, which means that half of the patients did not respond to OCA. Second, pruritus, a frequent symptom of PBC, appeared as an adverse effect in $56-68 \%$ of patients treated with OCA. Furthermore, whether the primary end points (ALP level $<1.67 \times$ ULN with $>15 \%$ reduction from the baseline and normal bilirubin level) are associated with improvement of long-term outcomes has not been confirmed yet [80]. In this regard, follow-up studies of the POISE trial were required by the FDA, and a phase 3 study is currently ongoing (COBALT, NCT02308111). Finally, OCA treatment should be continued for patients refractory to UDCA; thus, OCA may be prescribed lifelong along with UDCA. Based on the high cost of OCA $(\$ 69,350$ per year), this unlimited prescription of OCA may cause substantial economic burden on both patients and society, Samur et al. recently demonstrated that the price should be decreased to $\$ 18,450$ per year to make OCA cost-effective [81].

\section{Fibrates}

Fibrates (fenofibrate and bezafibrate) were originally labeled for dyslipidemia and used for decreasing serum cholesterol and triglycerides. Fibrates are PPAR-alfa and PXR agonists, resulting in reduction of de novo bile acid synthesis and up regulation of bile acid transporters [82]. Bezafibrate was first reported as biologically effective for PBC patients refractory to UDCA in 1999 [83]; since then, it has been used as an off-label second-line drug in Japan. A large-scale retrospective cohort study in Japan demonstrated that patients with good response to bezafibrate (normalization of ALT) exhibited a comparable prognosis to those treated with UDCA alone and significantly better outcomes than those with poor response to bezafibrate [84]. Recently, a prospective randomized study in Japan revealed that long-term outcomes were not significantly different between the UDCA plus bezafibrate and UDCA only groups, but the sample size in this study might be too small to establish enough statistical power [85]. Another prospective, randomized phase 3 study of bezafibrate for patients with PBC with incomplete responses to UDCA is ongoing in France (NCT01654731). Fenofibrate was reported to decrease serum ALP levels in studies in Japan and China $[86,87]$, while adjunct use of fenofibrate to UDCA showed no association with decreased serum ALP levels in a UK cohort [88]. Participants are being recruited for a prospective randomized study in China (NCT02965911). However, these two prospective clinical trials showed improved liver enzyme levels notably at 12 or 24 months as the primary end point. Even after these trials are terminated, whether long-term outcomes are improved with additional treatment with fibrates is still unknown, and follow-up studies of these trials are needed.

\section{Ileal bile acid transporter inhibitors}

Bile acids are essential to the human body, and $98 \%$ of bile acids excreted into the intestine are reabsorbed from the ileum bile acid transporter (IBAT) and returned to the liver via portal tract, known as enterohepatic circulation. In cholestatic liver disease, ileal bile acid absorption is increased [89]. Therefore, another strategy for reducing bile acids is blocking IBAT. One of these compounds, GSK2330672, did not significantly decrease serum ALP levels in patients with incomplete responses to UDCA but was demonstrated to significantly improve pruritus in comparison with placebo [90]. A prospective, randomized, placebo-controlled phase 2 study of GSK2330672 is launched in 2017 (NCT02966834).

\section{Future direction with the ARE $\mathrm{Del}^{-/-}$mouse model}

Although PBC is clearly a heterogeneous disease, the therapeutic approach is similar for all patients and not satisfactory at all even with OCA. This is partly due to the lack of animal models that could be used for investigating the immunopathology of PBC and the efficacy of newly developed compounds. In this regard, ARE Del ${ }^{-/-}$mice, which closely mimic human PBC, is currently the most attractive model. ARE Del ${ }^{-/-}$mice provides the following benefits. First, this is a female-predominant model for PBC, which allows for investigation on mechanisms of female predominance in the disease. We can conduct a comprehensive analysis on sexual dimorphic physiological systems, including hormones, immune differences, and microbiome. We can alter estrogen and estrogen receptors on cells to study their effect on disease process and pathology. We can also examine the female microbiome to resemble the male microbiome and raise these mice in a germ-free environment for further systematic introduction of selected bacteria. Second, this model will aid in determining which gene pathways may help or hinder the progress of PBC in both sexes. Third, this model also enables us to examine over time the interaction of multiple cellular messengers and their role in the development of autoimmune state. Finally, this model has 
vast implications for clinical research. It allows for examination of the heterogeneity and the natural history of PBC, from the early, asymptomatic stage to the late stage and the possibility to discover new biomarkers along different stages. This mouse also provides an effective tool for assessing the effect of drugs currently used or under development, and for designing novel, more-effective drugs for the clinical management of PBC.

\section{Conflict of interest}

The authors declare no conflict of interest.

\section{References}

1. Kaplan MM, Gershwin ME. Primary biliary cirrhosis. New Engl J Med 2005; 353: 1261-73.

2. Carey EJ, Ali AH, Lindor KD. Primary biliary cirrhosis. Lancet 2015; 386: 1565-75.

3. Hardtke-Wolenski M, Dywicki J, Fischer K, et al. The influence of genetic predisposition and autoimmune hepatitis inducing antigens in disease development. J Autoimmun 2017; 78: 39-45.

4. Hirschfield GM, Siminovitch KA. Genetics in PBC: what do the "risk genes" teach us? Clin Rev Allergy Immunol 2015; 48: 176-81.

5. Kerstein A, Schuler S, Cabral-Marques O, et al. Environmental factor and inflammation-driven alteration of the total peripheral T-cell compartment in granulomatosis with polyangiitis. J Autoimmun 2017; 78: 79-91.

6. Nielsen PR, Kragstrup TW, Deleuran BW, Benros ME. Infections as risk factor for autoimmune diseases - a nationwide study. J Autoimmun 2016; 74: 176-81.

7. Zhang H, Carbone M, Lleo A, Invernizzi P. Geoepidemiology, genetic and environmental risk factors for PBC. Dig Dis 2015; 33 Suppl 2: 94-101.

8. Marzorati S, Lleo A, Carbone M, Gershwin ME, Invernizzi P. The epigenetics of PBC: the link between genetic susceptibility and environment. Clin Res Hepatol Gastroenterol 2016; 40: 650-9.

9. Lindor KD, Gershwin ME, Poupon R, Kaplan M, Bergasa NV, Heathcote Ej; American Association for Study of Liver D. Primary biliary cirrhosis. Hepatology 2009; 50: 291-308.

10. Nevens F, Andreone P, Mazzella G, et al. A placebo-controlled trial of obeticholic acid in primary biliary cholangitis. N Engl J Med 2016; 375: 631-43.

11. Mousa HS, Carbone M, Malinverno F, Ronca V, Gershwin ME, Invernizzi P. Novel therapeutics for primary biliary cholangitis: toward a disease-stage-based approach. Autoimmun Rev 2016; 15: 870-6.

12. Yang $F$, Wang $Q$, Wang $Z$, et al. The natural history and prognosis of primary biliary cirrhosis with clinical features of autoimmune hepatitis. Clin Rev Allergy Immunol 2016; 50: 114-23.

13. Ali AH, Lindor KD. Obeticholic acid for the treatment of primary biliary cholangitis. Expert Opin Pharmacother 2016; 17: 1809-15.

14. de Vries E, Beuers U. Management of cholestatic disease in 2017. Liver Int 2017; 37 Suppl 1: 123-9.

15. Zhu C, Fuchs CD, Halilbasic E, Trauner M. Bile acids in regulation of inflammation and immunity: friend or foe? Clin Exp Rheumatol 2016; 34: 25-31.

16. Tang R, Wei Y, Li Y, et al. Gut microbial profile is altered in primary biliary cholangitis and partially restored af- ter UDCA therapy. Gut 2017 in press; doi: 10.1136/gutjnl-2016-313332.

17. Sun Y, Zhang W, Li B, Zou Z, Selmi C, Gershwin ME. The coexistence of Sjogren's syndrome and primary biliary cirrhosis: a comprehensive review. Clin Rev Allergy Immunol 2015; 48: 301-15.

18. Lleo A, Jepsen P, Morenghi E, et al. Evolving trends in female to male incidence and male mortality of primary biliary cholangitis. Sci Rep 2016; 6: 25906.

19. Terziroli Beretta-Piccoli B, Guillod C, Marsteller I, et al. Primary biliary cholangitis associated with skin disorders: a case report and review of the literature. Arch Immunol Ther Exp (Warsz) 2017 in press.

20. Amano K, Leung P, Rieger R, et al. Chemical xenobiotics and mitochondrial autoantigens in primary biliary cirrhosis: identification of antibodies against a common environmental, cosmetic, and food additive, 2-octynoic acid. J Immunol 2005; 174: 5874-83.

21. Cordell HJ, Han Y, Mells GF, et al. International genome-wide meta-analysis identifies new primary biliary cirrhosis risk loci and targetable pathogenic pathways. Nat Commun 2015; 6: 8019.

22. Dong M, Li J, Tang R, et al. Multiple genetic variants associated with primary biliary cirrhosis in a Han Chinese population. Clin Rev Allergy Immunol 2015; 48: 316-21.

23. Hirschfield GM, Liu X, Xu C, et al. Primary biliary cirrhosis associated with HLA, IL12A, and IL12RB2 variants. N Engl J Med 2009; 360: 2544-55.

24. Nakamura M, Nishida N, Kawashima M, et al. Genome-wide association study identifies TNFSF15 and POU2AF1 as susceptibility loci for primary biliary cirrhosis in the Japanese population. Am J Hum Genet 2012; 91: 721-8.

25. Webb GJ, Hirschfield GM. Using GWAS to identify genetic predisposition in hepatic autoimmunity. J Autoimmun 2016; 66: 25-39.

26. Lleo A, Zhang W, Zhao M, et al. DNA methylation profiling of the $X$ chromosome reveals an aberrant demethylation on CXCR3 promoter in primary biliary cirrhosis. Clin Epigenetics 2015; 7: 61.

27. Long H, Yin H, Wang L, Gershwin ME, Lu Q. The critical role of epigenetics in systemic lupus erythematosus and autoimmunity. J Autoimmun 2016; 74: 118-38.

28. Xie YQ, Ma HD, Lian ZX. Epigenetics and primary biliary cirrhosis: a comprehensive review and implications for autoimmunity. Clin Rev Allergy Immunol 2016; 50: 390-403.

29. Pollock RA, Abji F, Gladman DD. Epigenetics of psoriatic disease: a systematic review and critical appraisal. J Autoimmun 2017; 78: 29-38.

30. Shu Y, Hu O, Long H, Chang C, Lu O, Xiao R. Epigenetic variability of $C D 4+C D 25+$ Tregs contributes to the pathogenesis of autoimmune diseases. Clin Rev Allergy Immunol 2016; 52: 260-72.

31. He XS, Gershwin ME, Ansari AA. Checkpoint-based immunotherapy for autoimmune diseases - opportunities and challenges. J Autoimmun 2017; 79: 1-3.

32. Sun Y, Haapanen K, Li B, Zhang W, Van de Water J, Gershwin ME. Women and primary biliary cirrhosis. Clin Rev Allergy Immunol 2015; 48: 285-300.

33. Wang Q, Yang F, Miao Q, Krawitt EL, Gershwin ME, Ma X. The clinical phenotypes of autoimmune hepatitis: a comprehensive review. J Autoimmun 2016; 66: 98-107.

34. Rubtsova K, Marrack P, Rubtsov AV. TLR7, IFNgamma, and T-bet: their roles in the development of $A B C s$ in female-biased autoimmunity. Cell Immunol 2015; 294 : 80-3. 
35. Fish EN. The X-files in immunity: sex-based differences predispose immune responses. Nat Rev Immunol 2008; 8: 737-44.

36. Markle JG, Frank DN, Mortin-Toth S, et al. Sex differences in the gut microbiome drive hormone-dependent regulation of autoimmunity. Science 2013; 339: 1084-8.

37. Rosser EC, Mauri C. A clinical update on the significance of the gut microbiota in systemic autoimmunity. J Autoimmun 2016; 74: 85-93.

38. Shamriz O, Mizrahi H, Werbner M, Shoenfeld Y, Avni O, Koren O. Microbiota at the crossroads of autoimmunity. Autoimmun Rev 2016; 15: 859-69.

39. Arsenijevic A, Milovanovic M, Milovanovic J, et al. Deletion of galectin-3 enhances xenobiotic induced murine primary biliary cholangitis by facilitating apoptosis of BECs and release of autoantigens. Sci Rep 2016; 6: 23348.

40. Choi J, Selmi C, Leung PS, Kenny TP, Roskams T, Gershwin ME. Chemokine and chemokine receptors in autoimmunity: the case of primary biliary cholangitis. Expert Rev Clin Immunol 2016; 12: 661-72.

41. Hisamoto S, Shimoda S, Harada K, et al. Hydrophobic bile acids suppress expression of AE2 in biliary epithelial cells and induce bile duct inflammation in primary biliary cholangitis. J Autoimmun 2016; 75: 150-60.

42. Lleo A, Bian Z, Zhang H, et al. Quantitation of the RankRankl axis in primary biliary cholangitis. PLoS One 2016; 11: e0159612.

43. Ma HD, Ma WT, Liu QZ, et al. Chemokine receptor CXCR3 deficiency exacerbates murine autoimmune cholangitis by promoting pathogenic CD8+ T cell activation. J Autoimmun 2017; 78: 19-28.

44. Syu BJ, Loh CE, Hsueh YH, Gershwin ME, Chuang YH. Dual roles of IFN-gamma and IL-4 in the natural history of murine autoimmune cholangitis: IL-30 and implications for precision medicine. Sci Rep 2016; 6: 34884.

45. Hsueh YH, Chang YN, Loh CE, Gershwin ME, Chuang YH. AAV-IL-22 modifies liver chemokine activity and ameliorates portal inflammation in murine autoimmune cholangitis. J Autoimmun 2016; 66: 89-97.

46. Tomiyama T, Yang GX, Zhao M, et al. The modulation of co-stimulatory molecules by circulating exosomes in primary biliary cirrhosis. Cell Mol Immunol 2017; 14: 276-84.

47. Shuai Z, Wang J, Badamagunta M, et al. The fingerprint of antimitochondrial antibodies and the etiology of primary biliary colangitis. Hepatology 2017; 65: 1670-82.

48. Yang F, Yang Y, Wang Q, et al. The risk predictive values of UK-PBC and GLOBE scoring system in Chinese patients with primary biliary cholangitis: the additional effect of anti-gp210. Aliment Pharmacol Ther 2017; 45: 733-43.

49. Gershwin ME, Selmi C, Worman HJ, et al. Risk factors and comorbidities in primary biliary cirrhosis: a controlled interview-based study of 1032 patients. Hepatology 2005; 42: 1194-202.

50. Smyk DS, Rigopoulou EI, Lleo A, et al. Immunopathogenesis of primary biliary cirrhosis: an old wives' tale. Immun Ageing 2011; 8: 12.

51. Invernizzi P, Miozzo M, Battezzati PM, et al. Frequency of monosomy $X$ in women with primary biliary cirrhosis. Lancet 2004; 363: 533-5.

52. Selmi C, Invernizzi P, Miozzo M, Podda M, Gershwin ME. Primary biliary cirrhosis: does $\mathrm{X}$ mark the spot? Autoimmun Rev 2004; 3: 493-9.

53. Anaya JM, Ramirez-Santana C, Alzate MA, Molano-Gon zalez N, Rojas-Villarraga A. The autoimmune ecology. Front Immunol 2016; 7: 139.
54. Irie J, Wu Y, Wicker LS, et al. NOD.c3c4 congenic mice develop autoimmune biliary disease that serologically and pathogenetically models human primary biliary cirrhosis. J Exp Med 2006; 203: 1209-19.

55. Koarada S, Wu Y, Fertig N, et al. Genetic control of autoimmunity: protection from diabetes, but spontaneous autoimmune biliary disease in a nonobese diabetic congenic strain. J Immunol 2004; 173: 2315-23.

56. Oertelt S, Lian ZX, Cheng CM, et al. Anti-mitochondrial antibodies and primary biliary cirrhosis in TGF-beta receptor II dominant-negative mice. J Immunol 2006; 177: 1655-60.

57. Moritoki Y, Lian ZX, Lindor K, et al. B-cell depletion with anti-CD20 ameliorates autoimmune cholangitis but exacerbates colitis in transforming growth factor-beta receptor II dominant negative mice. Hepatology 2009; 50: 1893-903.

58. Wakabayashi K, Lian ZX, Moritoki Y, et al. IL-2 receptor alpha(-/-) mice and the development of primary biliary cirrhosis. Hepatology 2006; 44: 1240-9.

59. Aoki CA, Roifman CM, Lian ZX, et al. IL-2 receptor alpha deficiency and features of primary biliary cirrhosis. J Autoimmun 2006; 27: 50-3.

60. Salas JT, Banales JM, Sarvide S, et al. Ae2a,b-deficient mice develop antimitochondrial antibodies and other features resembling primary biliary cirrhosis. Gastroenterology 2008; 134: 1482-93.

61. Wakabayashi K, Lian ZX, Leung PS, et al. Loss of tolerance in C57BL/6 mice to the autoantigen E2 subunit of pyruvate dehydrogenase by a xenobiotic with ensuing biliary ductular disease. Hepatology 2008; 48: 531-40.

62. Kawata K, Tsuda M, Yang GX, et al. Identification of potential cytokine pathways for therapeutic intervention in murine primary biliary cirrhosis. PloS One 2013; 8: e74225.

63. Dhirapong A, Yang GX, Nadler S, et al. Therapeutic effect of cytotoxic T lymphocyte antigen 4/immunoglobulin on a murine model of primary biliary cirrhosis. Hepatology 2013; 57: 708-15.

64. Yang CY, Ma X, Tsuneyama K, et al. IL-12/Th1 and IL-23/ Th17 biliary microenvironment in primary biliary cirrhosis: implications for therapy. Hepatology 2014; 59: 1944-53.

65. Wang J, Yang GX, Tsuneyama K, Gershwin ME, Ridgway WM, Leung PS. Animal models of primary biliary cirrhosis. Semin Liver Dis 2014; 34: 285-96.

66. Zhang MA, Rego D, Moshkova M, et al. Peroxisome proliferator-activated receptor (PPAR)alpha and -gamma regulate IFNgamma and IL-17A production by human $T$ cells in a sex-specific way. Proc Natl Acad Sci USA 2012; 109: 9505-10.

67. Pelfrey CM, Cotleur AC, Lee JC, Rudick RA. Sex differences in cytokine responses to myelin peptides in multiple sclerosis. J Neuroimmunol 2002; 130: 211-23.

68. Hodge DL, Berthet C, Coppola V, et al. IFN-gamma AUrich element removal promotes chronic IFN-gamma expression and autoimmunity in mice. J Autoimmun 2014; 53: 33-45.

69. Bae HR, Leung PS, Tsuneyama K, et al. Chronic expression of interferon-gamma leads to murine autoimmune cholangitis with a female predominance. Hepatology 2016; 64: 1189-201.

70. Hirschfield GM, Gershwin ME, Strauss R, et al. Ustekinumab for patients with primary biliary cholangitis who have an inadequate response to ursodeoxycholic acid: a proof-of-concept study. Hepatology 2016; 64: 189-99.

71. Beuers U, Hohenester S, de Buy Wenniger LJ, Kremer AE, Jansen PL, Elferink RP. The biliary $\mathrm{HCO}(3)(-)$ umbrella: 
a unifying hypothesis on pathogenetic and therapeutic aspects of fibrosing cholangiopathies. Hepatology 2010; 52: 1489-96.

72. Beuers U, Gershwin ME, Gish RG, et al. Changing nomenclature for PBC: from 'cirrhosis' to 'cholangitis'. Hepatology 2015; 62: 1620-2.

73. Trauner M, Fuchs CD, Halilbasic E, Paumgartner G. New therapeutic concepts in bile acid transport and signaling for management of cholestasis. Hepatology 2017; 65: 1393-404

74. Myers RP, Swain MG, Lee SS, Shaheen AA, Burak KW. $B$-cell depletion with rituximab in patients with primary biliary cirrhosis refractory to ursodeoxycholic acid. Am J Gastroenterol 2013; 108: 933-41.

75. Tsuda M, Moritoki Y, Lian ZX, et al. Biochemical and immunologic effects of rituximab in patients with primary biliary cirrhosis and an incomplete response to ursodeoxycholic acid. Hepatology 2012; 55: 512-21.

76. Suresh T, Lee LX, Joshi J, Barta SK. New antibody approaches to lymphoma therapy. J Hematol Oncol 2014; 7: 58 .

77. Shimoda S, Harada K, Niiro H, et al. CX3CL1 (fractalkine): a signpost for biliary inflammation in primary biliary cirrhosis. Hepatology 2010; 51: 567-75.

78. Nanki T, Imai T, Kawai S. Fractalkine/CX3CL1 in rheumatoid arthritis. Mod Rheumatol 2017; 27: 392-7.

79. Pellicciari R, Fiorucci S, Camaioni E, et al. 6alpha-ethyl-chenodeoxycholic acid (6-ECDCA), a potent and selective FXR agonist endowed with anticholestatic activity. J Med Chem 2002; 45: 3569-72.

80. Trivedi PJ, Hirschfield GM, Gershwin ME. Obeticholic acid for the treatment of primary biliary cirrhosis. Expert Rev Clin Pharmacol 2016; 9: 13-26.

81. Samur S, Klebanoff M, Banken R, et al. Long-term clinical impact and cost-effectiveness of obeticholic acid for the treatment of primary biliary cholangitis. Hepatology 2017; 65: 920-8.

82. Honda A, Ikegami T, Nakamuta $M$, et al. Anticholestatic effects of bezafibrate in patients with primary biliary cirrhosis treated with ursodeoxycholic acid. Hepatology 2013; 57: 1931-41.

83. Iwasaki S, Tsuda K, Ueta $\mathrm{H}$, et al. Bezafibrate may have a beneficial effect in pre-cirrhotic primary biliary cirrhosis. Hepatol Res 1999; 16: 12-8.

84. Tanaka A, Hirohara J, Nakanuma Y, Tsubouchi H, Takikawa $\mathrm{H}$. Biochemical responses to bezafibrate improve long-term outcome in asymptomatic patients with primary biliary cirrhosis refractory to UDCA. J Gastroenterol 2015; 50: 675-82.

85. Hosonuma K, Sato K, Yamazaki Y, et al. A prospective randomized controlled study of long-term combination therapy using ursodeoxycholic acid and bezafibrate in patients with primary biliary cirrhosis and dyslipidemia. Am J Gastroenterol 2015; 110: 423-31.

86. Cheung AC, Lapointe-Shaw L, Kowgier M, et al. Combined ursodeoxycholic acid (UDCA) and fenofibrate in primary biliary cholangitis patients with incomplete UDCA response may improve outcomes. Aliment Pharmacol Ther 2016; 43: 283-93.

87. Dohmen K, Mizuta T, Nakamuta M, Shimohashi N, Ishibashi H, Yamamoto K. Fenofibrate for patients with asymptomatic primary biliary cirrhosis. World J Gastroenterol 2004; 10: 894-8.

88. Hegade VS, Khanna A, Walker LJ, Wong LL, Dyson JK, Jones DE. Long-term fenofibrate treatment in primary biliary cholangitis improves biochemistry but not the UK-PBC risk score. Dig Dis Sci 2016; 61: 3037-44.
89. Hofmann AF. Inappropriate ileal conservation of bile acids in cholestatic liver disease: homeostasis gone awry. Gut 2003; 52: 1239-41.

90. Hegade VS, Kendrick SF, Dobbins RL, et al. Effect of ileal bile acid transporter inhibitor GSK2330672 on pruritus in primary biliary cholangitis: a double-blind, randomised, placebo-controlled, crossover, phase 2a study. Lancet 2017; 389: 1114-3. 